\title{
Persepsi Penonton Studio Program Acara “Kick Andy" Di Metro Tv
}

\author{
(Studi Deskriptif Kualitatif Persepsi Penonton Edisi Melampaui Batas) \\ ${ }^{1}$ Nurdian Trianggoro Mukti ; ${ }^{2}$ Febriansyah Nataly \\ ${ }^{1.2}$ Program Sarjana Ilmu Komunikasi Sekolah Tinggi Ilmu Komunikasi Indonesia Maju \\ Jln. Harapan No. 50, Lenteng Agung - Jakarta Selatan 12610 \\ Telp: (021) 78894045, Email: iannovaselic@gmail.com ; febrixvai@gmail.com
}

\begin{abstract}
Abstrak
Persepsi dalam sebuah tayangan media massa merupakan hal penting untuk dikaji mengingat pengguna media massa dalam kehidupan sosial bukan sekedar sebagai pelepas ketegangan dan hiburan semata, akan tetapi isi dan informasi yang disajikan mempunyai tujuan yang sangat penting dalam proses tindakan persepsi. Metode Penelitian ini adalah deskriptif kualitatif dengan teknik pengumpulan data wawancara mendalam. Sumber data diperoleh melalui data primer yaitu wawancara Produser dan penonton program acara "Kick Andy". Sedangkan data sekunder diperoleh melalui berbagai tulisan artikel, buku-buku dan internet. Fokus penelitian ini meliputi persepsi yang di dalamnya terdapat sensasi, atensi dan respon serta Model SR dan Teori Perbedaan Individu. Berdasarkan hasil penelitian menunjukan bahwa persepsi penonton studio pada program acara "Kick Andy" Edisi Melampui Batas 2017 mempunyai persepsi yang berbeda-beda pada sensasi, Atensi (Perhatian) dan Respon namun berkesimpulan bahwa program acara "Kick Andy" adalah program acara yang menarik serta mengisi kebutuhan penonton studio dalam hal hiburan juga memberikan informasi/pengetahuan/wawasan sehingga mengubah persepsi penonton untuk mengikuti informasi/pengetahuan/wawasan yang didapatkan dari program acara "Kick Andy".
\end{abstract}

Kata Kunci: Persepsi, Penonton, Kick Andy

\begin{abstract}
Perception in a mass media impressions is an important thing to be studied considering the mass media users in social life is not just as a tension release and entertainment alone, but the content and information presented has a very important purpose in the process of perception action. The method of this research is qualitative descriptive with in-depth interview data collecting technique. The data source of primary data obtained through interviews Senior Producer and spectators of program "Kick Andy". While the secondary data obtained through a variety of writing articles, books and the internet. The focus of this research include the perception in which there is a sensation, attention and response as well as the Model SR and Theory of Individual Differences. Based on the results of research show that the perception of the spectator on the "Kick Andy" program Youth Pledge edition in 2017 have a different perception depending on the sensation, Attention and response, but concluded that the "Kick Andy" program is a program that is attractive as well as filling the needs of the spectator in terms of entertainment also provide information / knowledge / insight that changed the perception of the audience to follow the information / knowledge / insight gained from the program "Kick Andy".
\end{abstract}

Keyword : Perception, Audiences, Kick Andy 


\section{Pendahuluan}

Perkembangan media massa saat ini merupakan sebuah pendukung kebutuhan dalam aktifitas masyarakat. Dalam era globalisasi, teknologi yang berkembang dapat memudahkan masyarakat untuk mendapatkan informasi secara praktis dan efektif dengan mengikuti perkembangan zaman. Secara teori, media massa bertujuan menyampaikan informasi dengan benar secara efektif dan efesien kepada setiap khalayak. $^{1}$

Media massa merupakan alat yang digunakan dalam penyampaian pesan dari sumber kepada khalayak (penerima) dengan menggunakan alat-alat komunikasi mekanis seperti surat kabar, film, radio dan televisi pesan-pesan dari sumber kepada khalayak (menerima) dengan menggunakan alat-alat komunikasi mekanis seperti surat kabar, film, radio, $\mathrm{TV} .^{2}$

Media massa yang banyak digunakan dalam kehidupan sehari-hari umumnya adalah surat kabar, radio, televisi, dan film bioskop, yang beroperasi dalam bidang informasi, edukasi dan rekreasi, atau dalam istilah lain penerangan, pendidikan, dan hiburan.

Keuntungan komunikasi dengan menggunkan media massa adalah bahwa media massa menimbulkan keserempakan artinya suatu pesan dapat diterima oleh komunikan yang jumlah relatif banyak. Jadi untuk menyebarkan informasi, media massa sangat efektif yang dapat mengubah sikap, pendapat dan prilaku komunikasi. Bahwa pada dasarnya komunikasi massa adalah komunikasi melalui media massa yakni media cetak dan elektronik (Nurudin, 2007:3). ${ }^{3}$

Dibanding dengan media massa lainnya, televisi mempunyai sifat istimewa. Televisi merupakan gabungan dari media dengar dan gambar, bisa bersifat informatif, hiburan, maupun pendidikan, bahkan gabungan dari ketiga unsur diatas, Televisi merupakan sumber citra dan pesan tersebar (shared images and message) yang sangat besar dalam sejarah, dan ini telah menjadi mainstream bagi lingkungan simbolik masyarakat dan televisi merupakan sistem bercerita (Story-telling) yang tersentralisasi (Syahputra Iswandi, 2013:41). ${ }^{4}$

\section{Jurnal Ilmiah Komunikasi}

Secara langsung maupun tidak langsung, televisi memberikan pengaruh besar terhadap pola pikir masyarakat. Pesan yang disampaikan melalui media televisi mempunyai daya rangsang yang cukup tinggi, karena media televisi mempunyai fungsi sebagai informasi, hiburan, dan pendidikan. Siaran yang disajikan televisi kebanyakan bersifat hiburan seperti sinetron, kuis, infotaiment, talkshow, dan reality show. Televisi pada dasarnya tidak hanya sekedar sarana pelepas ketegangan atau hiburan, namun isi dan informasi apapun yang ditayangkan mempunyai pengaruh yang besar dalam kehidupan masyarakat. Sebab, apa yang ditayangkan oleh berbagai program acara televisi akan mempengaruhi kognisi khalayaknya.

Dengan adanya Realitas subjektif atau sebagaimana yang digambarkan Lippman dengan jargon "the world outside and the pictures in our head" yang dibentuk oleh media akan menjadi gambaran realitas publik tentang berbagai peristiwa sosial yang terjadi disekitarnya. Realitas inilah yang kemudian akan mendorong persepsi atau sikap khalayak terhadap berbagai hal tertentu.

Hal ini bisa dijadikan acuan bahwa penonton dalam mempersepsikan media televisi sebagai pusat informasi dan perkembangan jaman sehingga mempunyai peran penting dalam menyampaikan informasi kepada audience.

Mengingat pengguna media massa dalam kehidupan sosial bukan sekedar sebagai pelepas ketegangan dan hiburan, akan tetapi isi dan informasi yang disajikan mempunyai tujuan yang sangat penting dalam proses tindakan persepsi. Persepsi merupakan kesan yang diperoleh oleh individu melalui panca indera kemudian di analisa (diorganisir), diintepretasi dan kemudian dievaluasi sehingga individu tersebut memperoleh makna .

Tahap terpenting dalam persepsi adalah interpretasi yang kita peroleh melalui panca indra kita. Pengetahuan yang kita peroleh melalui persepsi bukan pengetahuan mengenai objek yang sebenarnya, melainkan pengetahuan mengenai bagaimana tampaknya objek tersebut. ${ }^{5}$

Penulis menyadari, bahwa penonton menjadi kajian penting dalam melihat seberapa besar perhatian dalam hal ini yang menimbulkan 
persepsi dalam diri penonton terhadap tayangan tersebut, terutama dalam persoalan kehidupan sehari hari. Sebab, tayangan ini bisa dikatakan sebagai media edukasi mengenai motivasi diri.

Dipenghujung dekade 1980-an dan awal dekade 1990-an suasana pertelevisian di Indonesia menjadi meriah, karena diperkenankannya pihak swasta mengelola stasiun televisi siaran. Munculnya stasiun TV swasta ini menguntungkan berbagai pihak, yakni dengan bertambahnya lapangan kerja dan bervariasinya program pada pesawat TV tanpa antena parabola yang harganya terlalu mahal bagi masyarakat umum. Stasiun televisi berlomba-lomba dalam menayangkan program acara yang menarik, mulai dari acara musik, sinetron, ftv, reality show, talkshow, feature, dan berita. Berdasarkan jumlah stasiun televisi di Indonesia, penulis memilih untuk lebih memfokuskan tulisan ini untuk membahas stasiun Metro TV. Metro TV tidak hanya berisi program berita saja, namun juga menyuguhkan beberapa acara talkshow.

Talkshow menjadi program unggulan di masing-masing stasiun televisi, Seperti hasil survei tahun 2015 oleh Komisi Penyiaran Indonesia (KPI) yang bekerja sama dengan Ikatan Sarjana Komunikasi Indonesia (ISKI) dan sejumlah perguruan tinggi terkemuka. Memberikan urutan program acara talkshow teratas di Indonesia yaitu Kick Andy Metro TV dengan penonton sebanyak 68,90 persen. Disusul dengan Mata Najwa Metro TV dengan angka 60,90 persen dan Hitam Putih Trans7 dengan perolehan 67,30 persen. Pada urutan keempat, ada Indonesia Lawyer's Club TV One (52,10 persen), Sarah Sechan Net TV (44,10 persen), Basa Basi Trans TV (34,00 persen), dan Satu Indonesia Net TV dengan raihan 25,20\%(https://m.tempo.co/read/news/2015/12/1 7/111728519/7-acara-talk-show-paling-banyakditonton-versi-survei-kpi). ${ }^{7}$

Metro TV memiliki beragam program acara, salah satunya yang menjadi unggulan adalah talk show Kick Andy yang mengudara sejak tanggal 1 Maret tahun 2006. Talk show Kick Andy merupakan salah satu program acara yang ditayangkan dan dikemas dalam bentuk perbincangan yang dapat memberikan pengetahuan berupa informasi kepada penonton.

\section{Jurnal Ilmiah Komunikasi}

Kick Andy ini mengangkat kisah hidup manusia yang terkadang sulit dipercaya jika semua itu benar-benar terjadi di sekitar kita. Talk show Kick Andy banyak berisi tentang kejadian seputar tokoh, orang-orang sukses atau masyarakat yang mempunyai pengalaman lebih dan menarik untuk dijadikan inspirasi agar memotivasi masyarakat yang menontonnya sehingga dapat melihat kehidupan orang disekeliling mereka dan lebih menghargai hidup dan waktu mereka.

Program acara "Kick Andy" merupakan salah satu program acara dengan format talkshow. Namun, "Kick Andy" sangat berbeda dengan program acara talkshow lainnya. Menonton program acara "Kick Andy" harus dengan hati, karena "Kick Andy" selalu menampilkan suatu peristiwa atau suatu tokoh, namun dari sudut pandang yang berbeda, dan dapat memberikan suatu persepsi inspirasi serta edukasi kepada penonton program acara "Kick Andy". Andy F. Noya sebagai pembawa acara, sekaligus pewawancara dalam program ini, mampu membawakan talkshow yang topik bahasanya serius, namun di tangan Andy $F$. Noya penonton merasa santai dan terhibur dalam menyimak program acara ini. Pertanyaanpertanyaan yang diajukan dan cara bertanya Andy F. Noya yang tidak menggurui atau menyudutkan pihak tertentu, membuat program acara "Kick Andy" semakin digemari oleh penontonnya, hal ini terbukti dengan bertahannya program acara "Kick Andy" selama kurun waktu kurang lebih 16 tahun. Program "Kick Andy" tayang pada hari Jumat pukul 20:05 - 21:35 WIB dan siaran ulangnya pada Sabtu 13:05 - 14:05 WIB .

Program acara televisi biasa menggunakan kisah inspiratif di Indonesia dalam membuat program acara yang menarik perhatian masyarakat seperti program acara "Kick Andy" edisi "Aksi nyata anak bangsa" sebuah kisah tentang seorang berkebutuhan khusus menjadi sukses dalam perjalanan hidupnya mencapai cita-cita, program merry riana edisi "Belajar dari yang kecil" sebuah kisah cara mendidik anak saat ini sangat berbeda dengan zaman dulu dan tantangan mendidik anak zaman sekarang sangatlah sulit, karena sumber informasi yang melimpah dan sulit untuk menyaringnya. Maka 
dari itu penulis melihat berbagai tema yang ada di program Kick Andy lainnya namun, ada satu edisi yang dianggap penulis sebagai sebuah program yang inspiratif dan memiliki rasa sosial yang tinggi serta menarik untuk di teliti yakni program Kick Andy di Metro Tv edisi "Melampaui Batas" dengan keterbatasan fisik yang dimiliki para nara sumber namun tetap berprestasi di bidangnya masing-masing dan menjadi sumber inspirasi bagi penonton. Pemberian episode inspiratif pada sebuah program acara biasanya mengikuti trend yang sedang berkembang. Maka tak heran jika kisah inspiratif menjadi pilihan di beberapa program acara talk show.

Hal ini menyebabkan tantangan bagi program televisi untuk menarik perhatian penonton sebanyak mungkin akan tetapi persoalan persepsi penonton yang tidak sama satu dengan yang lainnya menjadi tantangan untuk penulis membuat penelitian bagaimana proses persepsi terbentuk. Kick Andy memang layak menjadi salah satu program dengan penilaian tertinggi dalam kancah pertevisian Indonesia. Kick Andy sebagai sebuah program secara rutin menghadirkan sosok-sosok inspiratif dan menjadi program talkshow cukup banyak ditonton, hal ini patut mendapat ancungan jempol karena selalu menghadirkan para ahli serta responden menunjukkan bahwa program yang positif juga mampu menarik perhatian penonton. Talkshow yang selalu menyebarkan inspirasi bagi negeri dan pertahankan kualitas siaran agar dapat mempengaruhi program lainnya untuk juga menghadirkan tayangan yang lebih positif dan mendidik.

Penulis menyadari, bahwa penonton studio menjadi kajian penting dalam melihat seberapa besar perhatian dalam hal ini yang menimbulkan persepsi dalam diri penonton terhadap tayangan tersebut, sebab tayangan ini bisa dikatakan sebagai media edukasi mengenai sosial serta kisah inspiratif.

\section{Metode}

Penulis melakukan penelitian ini menggunakan metode penelitian kualitatif. Dimana dalam penelitian kualitatif sendiri bertujuan untuk menjelaskan fenomena dengan sedalam- dalamnya melalui pengumpulan data

\section{Jurnal Ilmiah Komunikasi}

observasi dan wawancara dengan menekankan persoalan kedalaman kualitas data bukan hanya banyaknya kuantitas data. Tahap penelitian kualitatif melampaui berbagai tahapan berpikir kritis- ilmiah, yang mana seorang peneliti memulai berpikir secara induktif, yaitu menangkap berbagai fakta atau fenomenafenomena sosial, melalui pengamatan di lapangan, kemudian menganalisisnya dan kemudian berupaya melakukan teori berdasarkan apa yang diamati itu. Peneliti diarahkan oleh produk berpikir induktif untuk menemukan jawaban logis terhadap apa yang sedang menjadi pusat perhatian dalam penelitian dan akhirnya produk berpikir induktif menjadi jawaban sementara terhadap apa yang dipertanyakan dalam penelitian dan menjadi perhatian itu, jawaban tersebut dinamakan berpikir induktif-analitis ${ }^{8}$.

Peneliti melakukan penelitiannya di Jl. Pilar Mas Raya Kav. A-D, Kedoya - Kebon Jeruk Jakarta 11520 - Indonesia Tlp:021-58300077 Fax: 021-58300066.

Sifat penelitian yang digunakan peneliti adalah studi kasus. Studi kasus merupakan salah satu jenis penelitian kualitatif, dimana peneliti melakukan eksplorasi secara mendalam terhadap program, kejadian, proses, aktivitas, terhadap satu atau lebih orang. Suatu kasus terkait oleh waktu dan aktivitas dan peneliti melakukan pengumpulan berbagai prosedur pengumpulan data dan dalam waktu yang berkesinambungan.

Teknik pengumpulan data yang digunakan dalam penelitian ini meliputi:

1. Data Primer, Sumber primer adalah sumber data yang langsung memberikan data kepada pengumpulan data. Teknik pengumpulan data untuk data primer yang digunakan dalam penelitian ini adalah wawancara, observasi, dan kuesioner.

2. Data Sekunder, Data sekunder umumnya berbentuk catatan atau laporan data dokumentasi oleh lembaga atau instansi tertentu yang dipublikasikan.Teknik pengumpulan data sekunder yang digunakan pada penelitian ini adalah dengan melakukan studi kepustakaan dalam bentuk buku, dokumen-dokumen, laporan tahunan yang berhubungan dengan masalah yang diteliti serta analisis dokumen,observasi dan 
wawancara. Data sekunder juga didapatkan dari materi-materi publikasi dari lembaga/instansi yang dapat digunakan sebagai bahan penunjang dalam penelitian.

Aktivitas dalam analisis meliputi reduksi data penyajian data, serta penarikan kesimpulan dan verifikasi. Untuk pengujian kredibilitas data, peneliti juga menggunakan triangulasi dalam teknik pengumpulan data. Triangulasi adalah teknik pengumpulan data yang bersifat menggabungkan dari berbagai teknik pengumpulan data dan sumber data yang telah ada . Triangulasi dapat dibedakan menjadi dua macam, yaitu triangulasi teknik dan triangulasi sumber. Triangulasi teknik adalah peneliti menggunakan teknik pengumpulan data yang berbeda-beda untuk mendapatkan data dari sumber data yang sama. Triangulasi dalam peneliti ini adalah triangulasi teknik dan triangulasi sumber karena peneliti melakukan dengan cara mengecek data kepada sumber dan teknik yang berbeda.. Triangulasi teknik dan sumber dapat meningkatkan pemahaman peneliti tentang suatu persoalan yang ditemukan di lapangan.

Talkshow Kick Andy merupakan program acara yang menyampaikan pesan-pesan kemanusiaan atau informasi yang berkaitan dengan masyarakat dan tentunya masing-masing audiens mempunyai persepsi yang berbeda. Talk show memiliki daya tarik yang membuat acaranya dikemas dengan baik. Dalam daya tarik talk show, audiens akan mempersepsikannya dengan berbeda-beda.

\section{Pembahasan}

Dalam penelitian ini yang dibahas adalah persepsi penonton tentang program talk show Kick Andy di Metro TV. Daya tarik talk show menurut Fred Wibowo, diantaranya adalah presenter, topik pembicaraan dan narasumber. Berdasarkan hasil penelitian di lapangan tentang persepsi penonton studio di Metro Tv terhadap talkshow Kick Andy, analisis hasil dan pembahasan sebagai berikut :

Dalam membuat pertanyaan Depth interview, peneliti melakukan survey singkat terhadap penonton di studio untuk bahan acuan. Dalam survey tersebut penulis menggunakan Google Formulir untuk menyebarluaskan

\section{Jurnal Ilmiah Komunikasi}

kuesioner secara online kepada 50 penonton di studio. Pertanyaan yang penulis ajukan bertujuan untuk mengetahui pengetahuan penonton dan persepsi penonton yang berjumlah 13 (tiga belas) pertanyaan. Depth interview dilakukan melalui pertanyaan mewakili kebutuhan penulis dalam meneliti persepsi penonton studio.

Pertanyaan nomor 1 (satu) sampai dengan nomor 4 (empat) adalah pengetahuan mengenai program acara "Kick Andy", pertanyaan nomor 5 (lima) sampai dengan nomor 13 (tiga belas) adalah mengenai ketertarikan dan persepsi penonton dalam menonton "Kick Andy". Berdasarkan survey singkat yang dilakukan, didapatkan hasil sebagai berikut:

Mayoritas penonton program acara "Kick Andy" berusia 34 (tiga puluh empat) tahun dengan jumlah 20 (dua puluh) orang, kemudian untuk umur 50 (lima puluh) tahun dengan jumlah 10 (sepuluh) orang, 42 (empat puluh dua) tahun sebanyak 6 (enam) orang, 23 (dua puluh tiga) tahun sebanyak 3 (tiga) orang, kemudian 19 (sembilan belas) tahun sebanyak 2 (dua) orang, lalu 20 (dua puluh), 21 (dua puluh satu) dan 31 (tiga puluh satu) tahun masingmasing sebanyak 2 (empat) orang. Serta 3 (tiga) orang berumur 54 (lima puluh empat) tahun.

\section{Gambar 1. USIA PENONTON di STUDIO PROGRAM KICK ANDY}

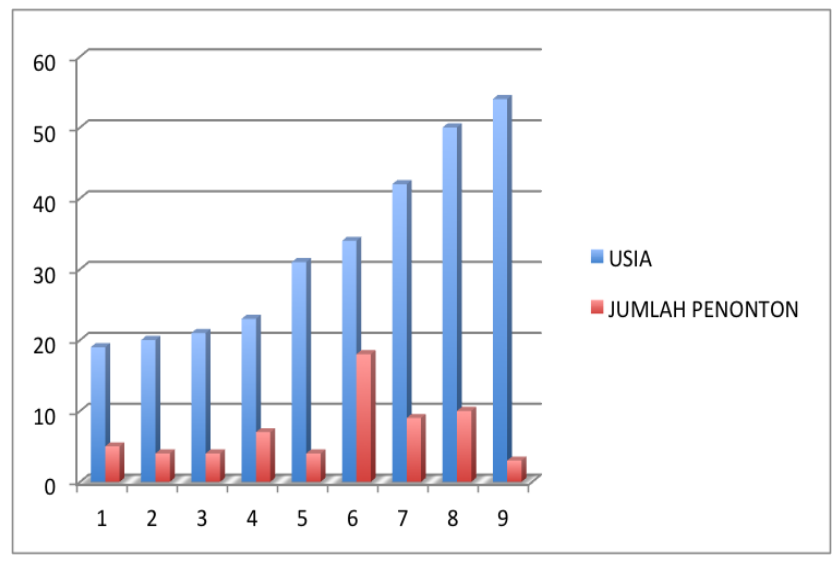

Telah didapatkan data dari keseluruhan penonton studio pada episode 5 Mei 2017 mengetahui program acara "Kick Andy".

\section{Gambar 2. Pengetahuan Program "Kick}


Andy"

\section{PENGETAHUAN TENTANG PROGRAM "KICK ANDY"}

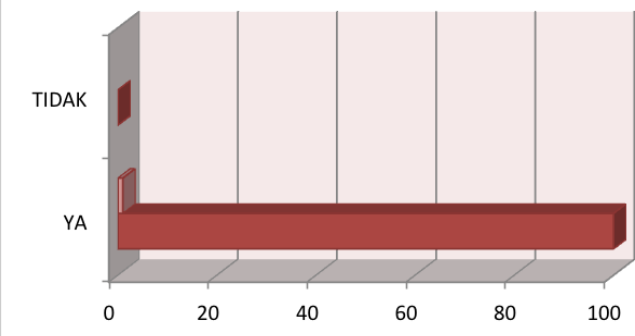

Kemudian hasil survey singkat mendapatkan bahwa keseluruhan penonton di studio mengatakan program acara "Kick Andy" menarik.

\section{Gambar 3. Ketertarikan dengan program acara "Kick Andy"}

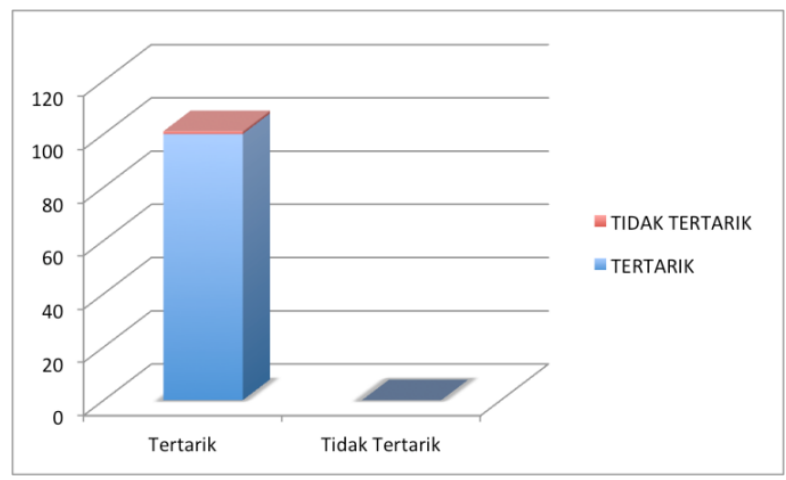

Dan hasil survey mendapatkan hasil bahwa sebanyak 47 penonton atau $32 \%$ mengatakan tertarik dengan Host program acara "Kick Andy", sebanyak 38 penonton atau 26\% tertarik dengan Bintang Tamu, sebanyak 32 penonton atau $22 \%$ tertarik dengan Tema dan sebanyak 29 penonton atau 20\% penonton tertarik dengan pembagian buku gratis. Semua data yang didapatkan menjadi dasar untuk membuat pertanyaan dalam Indepth Interview penelitian.

\section{Gambar 4. Hal yang membuat}

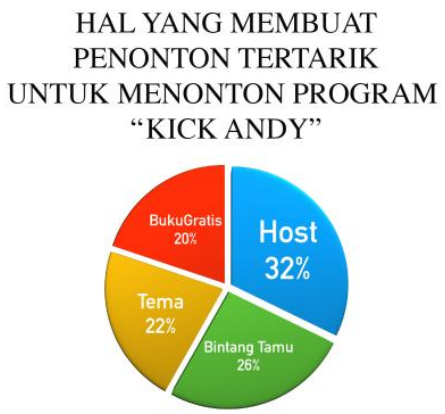

PENONTON TERTARIK

"KICK ANDY"

penonton tertarik dengan program acara

"Kick Andy"

Dengan adanya survey singkat ini dapat

$\square$

$\square$ dan menjadi dasar pertanyaan dalam Depth Interview terhadap key informan serta infroman 1 dan 2 yang menjadi dasar Depth Interview penelitian ini.

Persepsi penonton dalam progam acara "Kick Andy" menjadi pokok penelitian penulis, maka penulis menggunakan prinsip SR (Stimulus-Respon) dalam menjelaskan penelitian. Prinsip SR yang penulis gunakan terdiri dari:

1. Stimulus : Pribadi yang berbeda-beda membuat perbedaan pula dalam mempersepsikan suatu obyek. Hal ini disebabkan oleh faktor internal, yaitu mencakup fisiologis, perhatian, kebutuhan, pengalaman dan ingatan serta suasana hati. Dan faktor eksternal, Adapun yang meliputi faktor-faktor eksternal, yaitu: ukuran dan penempatan dari obyek (Stimulus), warna dari obyek, keunikan dan kekontrasan obyek, intensitas dan kekuatan stimulus, serta motion/gerakan dari stimulus. Penonton menerima stimulus pada program acara "Kick Andy " edisi 05 Mei 2017, sehingga penonton dapat mengetahui alur dan set panggung dari tayangan tersebut, karena stimulus dapat diamati oleh penonton yang ditangkap oleh indera penglihatan dan indera pendengaran kemudian otak merespon dan menimbulkan persepsi penonton

2. Respon : Respon dimaksud sebagai reaksi, tanggapan, jawaban, pengaruh, efek atau akibat, jadi dalam teori ini respon adalah tanggapan dari stimulus yang dihadirkan kepada penonton. Hal ini berkaitan dengan Teori Stimulus Response yaitu merupakan suatu prinsip belajar yang sederhana, dimana 
efek merupakan reaksi terhadap stimulus tertentu. Dengan demikian seseorang dapat memahami kaitan antara pesan pada media dan reaksi audien. Karakteristik individu, harapan dan persepsi terhadap media dan tingkat akses pada media akan membawa individu kepada keputusan untuk menggunakan atau tidak menggunakan isi media massa. Respon penonton program acara "Kick Andy" setiap harinya akan menimbulkan reaksi tergantung dari stimulus yang mereka terima. Respon dalam program acara "Kick Andy" 5 Mei 2017 menjadikan penonton agar dapat lebih mensyukuri dan bersemangat ketika menghadapi setiap kejadian dalam kehidupan dengan menghadirkan narasumber muda berprestasi namun dengan keterbatasan mampu mencapai kesuksesan sehingga dapat menginspirasi para pemuda-pemudi di jaman sekarang.

\section{Kesimpulan}

Berdasarkan hasil penelitian, kesimpulan yang dapat disampaikan dari penelitian Skripsi Persepsi Penonton Studio Program Acara "KICK ANDY" di METRO TV (Studi Deskriptif Kualitatif Persepsi Penonton Edisi Melampaui Batas) yang pertama adalah

Persepsi Penonton Kick Andy di Metro Tv Edisi Melampaui Batas, dari hasil survey singkat mendapatkan hasil bahwa sebanyak 47 penonton atau 32\% mengatakan tertarik dengan Host program acara "Kick Andy", sebanyak 38 penonton atau $26 \%$ tertarik dengan Bintang Tamu, sebanyak 32 penonton atau $22 \%$ tertarik dengan Tema dan sebanyak 29 penonton atau $20 \%$ penonton tertarik dengan pembagian buku gratis.

Kemudian Proses Persepsi Penonton Kick Andy di Metro Tv Edisi Melampaui Batas berjalan dengan baik hal ini terjadi beberapa faktor dari Stimulus yang disampaikan dalam acara ini mampu memberikan pesan positif kepada penonton yang ada di studio sehingga memberi respon positif terhadap tayangan ini. Hal ini juga tidak lepas dari karakteristik tiap individu yang berbeda antara satu dengan yang lainnya.

\section{Saran}

\section{Jurnal Ilmiah Komunikasi}

Berdasarkan hasil penelitian, berikut saran-saran yang di dapat agar dapat mengetahui proses persepsi penonton studio, yang pertama harus dilakukan adalah mengetahui

Tema yang diangkat dari tayangan Kick Andy yang menghadirkan sosok inspiratif agar tayangan ini tetap menjadi leader program talk show yang menginspirasi dan memberikan motivasi kepada penonton yang menyaksikan program ini lalu kemudian

Gimmick yang ada pada talk show ini lebih sering dihadirkan di tengah tengah proses tapping kepada penonton untuk menghibur penonton yang hadir di studio kemudian

Set alat tapping diberi jarak antara penonton dengan crew agar penonton yang hadir tidak terganggu penglihatannya dengan keberadaan set alat disekitar penonton.

\section{Daftar Pustaka}

1. Alex Sobur. Semiotika Komunikasi. Bandung: Remaja Rosdakarya;2004

2. Cangara, Hafied. Pengantar Ilmu Komunikasi. Jakarta: PT Raja Grafindo Persad; 2002

3. Nurudin. Pengantar Komunikasi Massa. Jakarta : PT. Rajagrafindo Persada; 2007

4. Iswandi, Syahputra. Rezim Media Pergulatan Demokrasi, Jurnalisme dan Infotainment dalam Industri Televisi. Jakarta: Gramedia Pustaka Utama; 2013

5. Deddy Mulyana.Ilmu Komunikasi. Bandung: PT. Rosdakarya; 2010

6. Onong Uchjana Effendy.Ilmu Teori dan Filsafat komunikasi, Bandung: Citra Aditya; 2003

7. Artikel 7 Acara Talk Show Paling Banyak Ditonton Versi Survei KPI oleh Arif Arianto Diakses dari https://m.tempo.co/read/news/2015/12/17/1 11728519/7- acara-talk-show-palingbanyak-ditonton-versi-survei-kpi). tanggal 20 Juni 2017 


\section{Jurnal Ilmiah Komunikasi}

8. Bungin Burhan. Penelitian Kualitatif. Jakarta: Kencana Predana Media Group; 2011 